\title{
Retraction
}

\section{Retracted: An Unusual Case of Bilateral Vitreous Haemorrhage following Snake Bite}

\author{
Case Reports in Medicine \\ Received 16 November 2017; Accepted 16 November 2017; Published 18 January 2018 \\ Copyright (C) 2018 Case Reports in Medicine. This is an open access article distributed under the Creative Commons \\ Attribution License, which permits unrestricted use, distribution, and reproduction in any medium, provided the original \\ work is properly cited.
}

Case Reports in Medicine has retracted the article titled "An Unusual Case of Bilateral Vitreous Haemorrhage following Snake Bite" [1]. The article was found to contain a substantial amount of material from the following published articles: "Bhalla, A. et al., "Central retinal artery occlusion: an unusual complication of snakebite," Journal of Venomous Animals and Toxins Including Tropical Diseases, Botucatu, vol. 10, no. 3, pp. 311-314, 2004, doi: 10.1590/S167891992004000300009"; "Jae Seok Kim et al. "Coagulopathy in patients who experience snakebite," Korean Journal of Internal Medicine, vol. 23, no. 2, pp. 94-99, 2008, doi: 10.3904/kjim.2008.23.2.94"; "Tungpakorn, N., "Unusual visual loss after snakebite," Journal of Venomous Animals and Toxins Including Tropical Diseases, Botucatu, vol. 16, no. 3, pp. 519-523, 2010, doi: 10.1590/S1678-91992010000300020"; and "Rao, B. M., "A case of bilateral vitreous haemorrhage following snake bite," Indian Journal of Ophthalmology, vol. 25, no. 1-2, 1977. http://www.ijo.in/article.asp?issn=0301-4738; year $=1977$; volume $=25 ;$ issue $=2$; page $=1$; epage $=2$; aulast $=$ Rao. ${ }^{\text {” }}$

\section{References}

[1] V. Bhandari and M. Lohia, "An unusual case of bilateral vitreous haemorrhage following snake bite," Case Reports in Medicine, vol. 2013, Article ID 640582, 2 pages, 2013. 


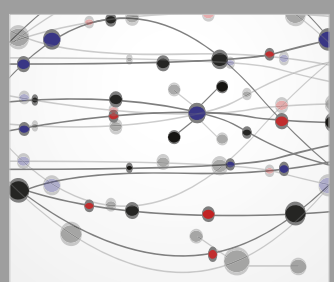

The Scientific World Journal
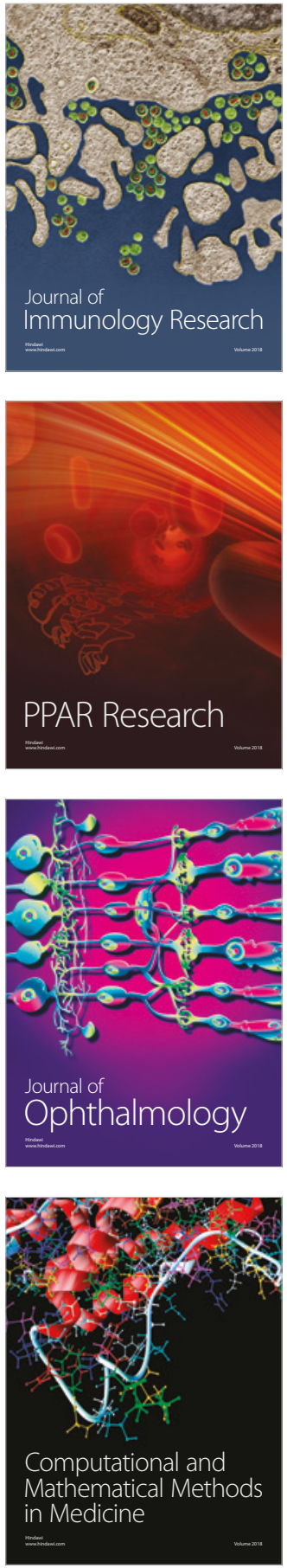

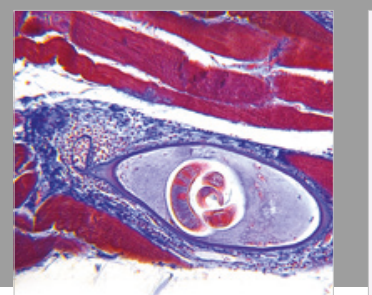

Gastroenterology Research and Practice

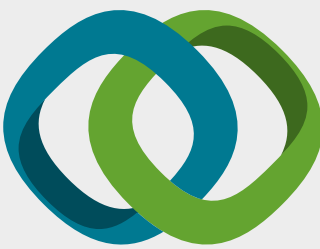

\section{Hindawi}

Submit your manuscripts at

www.hindawi.com
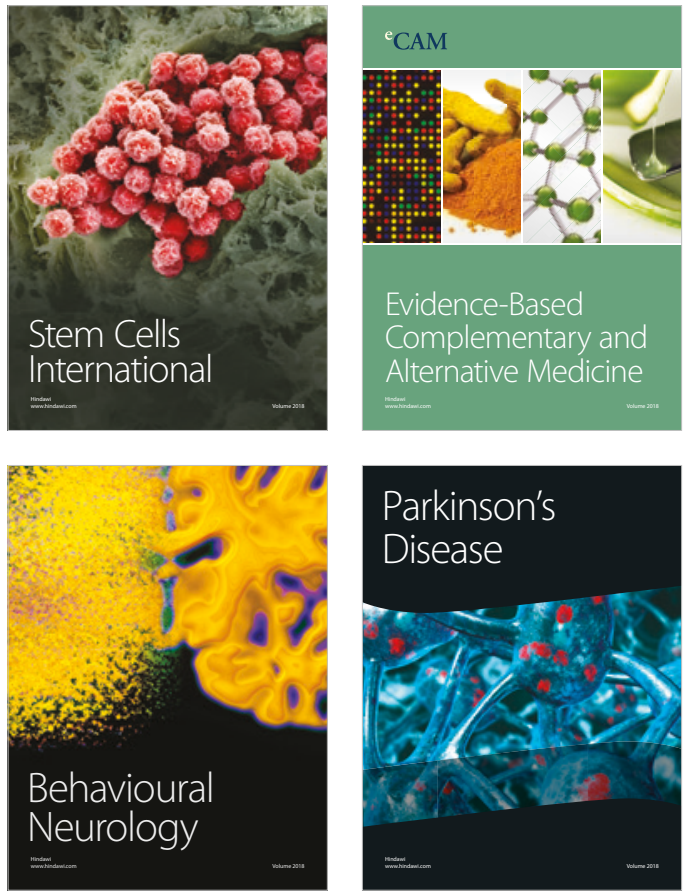

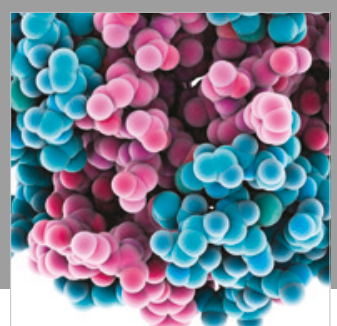

ournal of

Diabetes Research

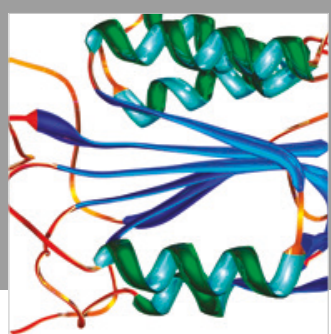

Disease Markers
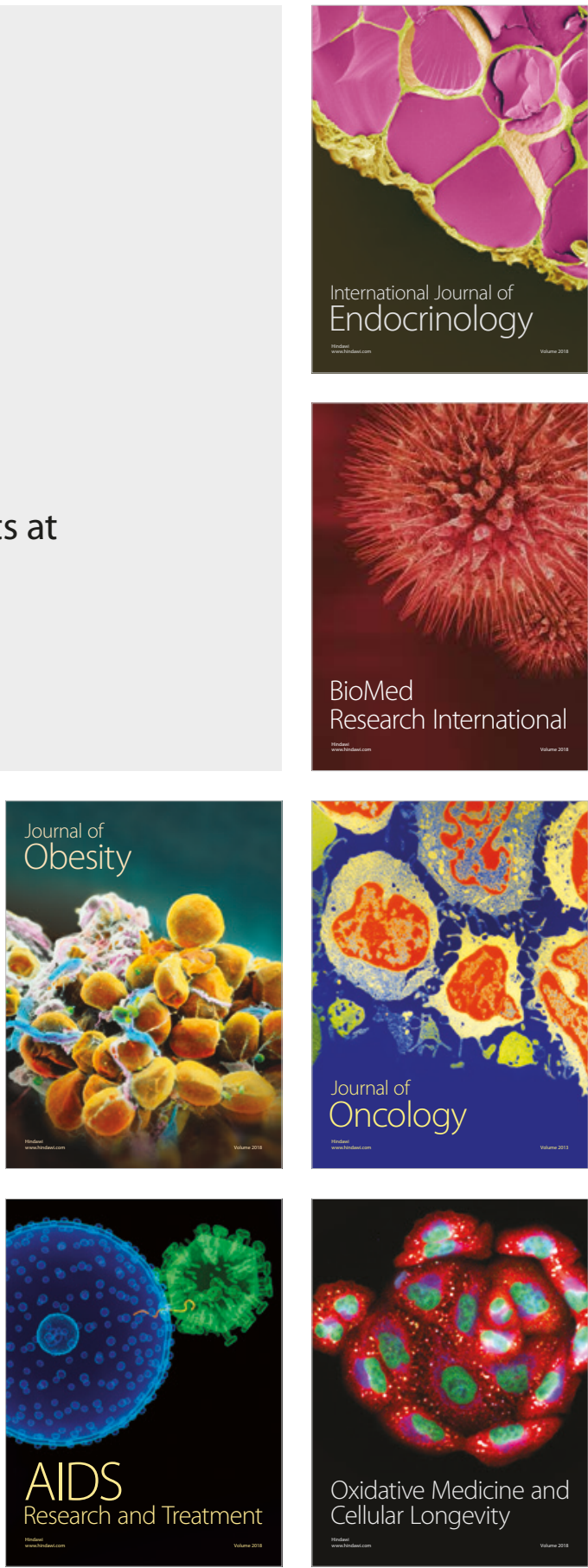